\title{
Aortic root morphology in patients undergoing percutaneous aortic valve replacement: Evidence of aortic root remodeling
}

\author{
Mateen Akhtar, MD, ${ }^{a}$ E. Murat Tuzcu, MD, ${ }^{\text {a }}$ Samir R. Kapadia, MD, ${ }^{a}$ Lars G. Svensson, MD, PhD, ${ }^{b}$ Roy K. Greenberg, MD, \\ Eric E. Roselli, MD, ${ }^{\mathrm{b}}$ Sandra Halliburton, PhD, ${ }^{\mathrm{d}}$ Vikram Kurra, MBBS,,${ }^{\mathrm{a} d}$ Paul Schoenhagen, MD, ${ }^{\mathrm{a}, \mathrm{d}}$ and Srikanth Sola, MD ${ }^{\mathrm{a}, \mathrm{d}}$
}

\begin{abstract}
Objective: Percutaneous aortic valve replacement is an emerging therapy for selected patients with severe aortic stenosis. Preoperative imaging of the aortic root facilitates sizing and deployment of the percutaneous aortic valve replacement device. We compared morphologic characteristics of the aortic root in patients with aortic stenosis versus elderly gender-matched controls using multidetector computed tomography.
\end{abstract}

\begin{abstract}
Methods: Twenty-five consecutive subjects with severe calcific aortic stenosis referred for percutaneous aortic valve replacement and 25 elderly gender-matched controls were scanned on a Siemens Definition Dual Source (Siemens Medical, Forchheim, Germany) multidetector computed tomography scanner. Distances from the valve annulus to the coronary artery ostia and sinotubular junction, dimensions of the aortic root, and characteristics of the valve cusps were determined.
\end{abstract}

Results: Subjects with aortic stenosis had reduced distance from the aortic valve annulus to the inferior margins of the left and right coronary artery ostium and sinotubular junction compared with controls. There were no significant differences in cross-sectional dimensions of the aortic root.

Conclusion: The distance from the aortic valve annulus to the coronary artery ostia and sinotubular junction is reduced in patients with aortic stenosis compared with controls. This finding suggests that longitudinal remodeling of the aortic root occurs in calcific aortic stenosis and has implications for the design and deployment of percutaneous aortic valve replacement devices.

Percutaneous aortic valve replacement (PAVR) is an emerging therapy for selected patients with severe aortic stenosis (AS) who may not be candidates for conventional surgical valve replacement because of multiple comorbidities. ${ }^{1-4}$ Detailed knowledge of aortic valve and aortic root morphology, including the longitudinal distance from the aortic annulus to the coronary arteries and annular diameters, is important for preprocedural planning and device deployment.

However, our understanding of the complex 3-dimensional anatomy of the aortic valve and aortic root in calcific AS is incomplete. Although there is currently no uniform method for the evaluation of the aortic valve and root before PAVR, a combination of transthoracic or transesophageal echocardiography and fluoroscopy is typically used. Both standard echocardiography and fluoroscopy, however, are limited in their ability to evaluate the 3-dimensional characteristics of the aortic root, as well as the relationship of the aortic valve cusps to the coronary ostia. In contrast, highresolution interactive datasets obtained with multidetector

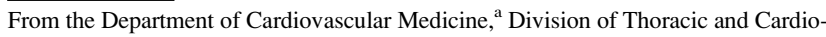
vascular Surgery, ${ }^{\mathrm{b}}$ Department of Vascular Surgery, ${ }^{\mathrm{c}}$ and Division of Radiology, ${ }^{\mathrm{d}}$ Cleveland Clinic Foundation, Cleveland, Ohio.

Received for publication May 25, 2008; revisions received July 16, 2008; accepted for publication July 31, 2008.

Address for reprints: Srikanth Sola, MD, FACC, FAHA, Department of Cardiovascular Medicine, The Cleveland Clinic, 9500 Euclid Avenue, Desk F-15, Cleveland, OH 44195 (E-mail: solas@ccf.org).

J Thorac Cardiovasc Surg 2009;137:950-6

$0022-5223 / \$ 36.00$

Copyright (c) 2009 by The American Association for Thoracic Surgery doi:10.1016/j.jtcvs.2008.07.062 computed tomography (MDCT) provide detailed anatomic information of the aortic valve and root, including their 3dimensional relationship. ${ }^{5-9}$ Additional cine computed tomography (CT) images ("4-dimensional") allow limited correlation between anatomy and function.

We hypothesized that dimensions of the aortic root are decreased and that its relationship to the coronary artery ostia is altered in patients with AS. By using MDCT, we therefore evaluated morphologic characteristics of the aortic root in patients with calcific AS versus elderly gendermatched controls.

\section{MATERIALS AND METHODS}

\section{Study Design and Patient Selection}

We enrolled a total of 50 subjects, including 25 consecutive subjects with calcific degenerative AS who were referred for PAVR because of a high risk of mortality with conventional aortic valve replacement, and 25 elderly gender-matched historical controls referred for coronary CT angiography for evaluation of chest pain. In accordance with current exclusion criteria from PAVR trials, patients with congenital unicuspid or bicuspid aortic valve, prior valvular heart surgery, mixed aortic valve disease (AS and aortic insufficiency with $\geq 3+$ aortic insufficiency), greater than or equal to $3+$ mitral insufficiency, or abdominal or thoracic aortic aneurysms greater than $5.0 \mathrm{~cm}$ were excluded. In addition, patients with relative contraindications for MDCT, including atrial fibrillation or advanced renal insufficiency, were excluded. Data collection and analysis were performed with approval by the institutional review board.

\footnotetext{
Multidetector Computed Tomography

Subjects were scanned on a Siemens Definition Dual Source MDCT scanner (Siemens Medical, Forchheim, Germany) after administration of a non-ionic, iodinated contrast agent $(80-100 \mathrm{~mL}$ Ultravist 370 , Bayer Healthcare, Berlin, Germany) at 4 to $5 \mathrm{~mL} / \mathrm{sec}$ followed by 30 to $50 \mathrm{~mL}$
} 


$$
\begin{aligned}
& \text { Abbreviations and Acronyms } \\
& \begin{aligned}
\text { AS } & =\text { aortic stenosis } \\
\mathrm{CT} & =\text { computed tomography } \\
\mathrm{MDCT} & =\text { multidetector computed tomography } \\
\mathrm{PAVR} & =\text { percutaneous aortic valve replacement }
\end{aligned}
\end{aligned}
$$

of normal saline at the same rate. A contrast bolus monitoring technique ${ }^{10}$ using a region of interest in the ascending aorta was used to determine the scan delay time. Once the desired attenuation (determined visually by the technologist) was reached, scanning was initiated in the craniocaudal direction during a single inspiratory breath-hold. Patients referred for PAVR were scanned from the level of the carina to the mid-left ventricle. Control patients who underwent coronary $\mathrm{CT}$ angiography were scanned from the level of the carina to the diaphragm. Control patients also received intravenous metoprolol (mean dose $11 \pm 3 \mathrm{mg}$ ) and sublingual nitroglycerin 0.3 $\mathrm{mg}$ before study acquisition as part of their examination protocol. Spiral data were acquired with retrospective electrocardiogram gating using the following parameters: gantry rotation time $=330 \mathrm{~ms}$; beam collimation $=32 \times 0.6 \mathrm{~mm}$; tube voltage $=120 \mathrm{kV}$; tube current-time product per rotation $=250$ to $410 \mathrm{mAs} / \mathrm{rot}$; and beam pitch $=0.2$ to 0.5 . Electrocardiogram-based tube current modulation was used for all patients with a reduction in tube current by $80 \%$ during systolic phases. Images were reconstructed during 10 to 14 phases of the cardiac cycle depending on patient heart rate with a temporal resolution of $83 \mathrm{~ms}$ and section thickness of 0.75 $\mathrm{mm}$. The average effective radiation dose was approximated for each patient after scanning by multiplying the dose-length product and a conversion factor for the chest. ${ }^{11}$

\section{Data Analysis}

Images were analyzed by consensus of 2 investigators on a dedicated CT workstation (Siemens Leonardo, Siemens Medical) equipped with Circulation and InSpace software. The largest cross-sectional diameters of the left ventricular outflow tract, aortic annulus, sinuses of Valsalva, and sinotubular junction were measured in systole ( $20 \%-30 \%$ phase) using double oblique images to identify the true short axis (Figure 1). The aortic valve annulus was defined at the lowest level of the insertion of the valve cusps into the aortic root; ${ }^{12}$ the maximal diameter at this point was determined as the maximal aortic valve annulus diameter. The annulus was defined as oval if the difference between the minimal and maximal cross-sectional diameters of the annulus was greater than $3 \mathrm{~mm}$. The maximum diameter of the sinus of Valsalva was determined from measurements extending from each commissure to the middle of the opposite coronary cusp. The sinotubular junction was measured at the junction of the sinuses and tubular portion of the ascending aorta. The vertical distances from the aortic valve annulus to the inferior margins of the left coronary artery ostium, right coronary artery ostium, and sinotubular junction were measured in systole and end diastole from oblique coronal views (Figure 2). Measurements were made in areas of minimal calcification to minimize the effect of calcium blooming artifact from calcified aortic valves. In a subset of 4 patients who underwent MDCT scanning after PAVR, we also measured the distance from the superior aspect of the device to the coronary artery ostia in systole. Leaflet height was defined as the longest length of the cusp from the annulus to the cusp tip and was measured in diastole ( $70 \%$ phase) from the long-axis view going through the center of each cusp (Figure 3). Effective cusp height was defined as the vertical distance from the annulus to each cusp tip and was measured in diastole from the long-axis view through the center of each cusp ${ }^{13}$ (Figure 3). Cusp-free margin length was measured in diastole from the short-axis view (Figure 4).

Aortic valve opening in the AS group was described qualitatively and quantitatively. The systolic valve orifice was examined on short-axis cine $\mathrm{CT}$ reconstructions and described as either symmetric and star-shaped or asymmetric. Quantitatively, the aortic valve area was determined by planimetry of the aortic valve using a plane parallel to the short axis of the aortic root. The time point of maximal aortic valve opening was identified during systole (usually at $20 \%-30 \%$ of the R-R interval). The area of the aortic valve opening was found by scrolling through the short-axis images toward the tip of the cusps until the smallest opening was found. The planimetered aortic valve area was determined by tracing the inside borders of the coronary cusps with electronic calipers and reported in square centimeters.

\section{Transthoracic Echocardiography}

All measurements were performed using a standard sonographic system equipped with a 3.5 to $1.75-\mathrm{MHz}$ transducer by an experienced observer. The peak and mean transvalvular velocities were measured in all patients using standard echocardiographic views. In addition, the aortic valve area was calculated using the continuity equation approach with a Doppler velocity-time integral. ${ }^{14}$ The mean and peak transvalvular pressure gradients were calculated. Left ventricular ejection fraction was determined using Simpson's method. ${ }^{15}$ Measurement of the aortic valve annulus was performed from the parasternal long-axis view from the point of insertion of the cusps into the aortic root.

\section{Statistical Analysis}

All values presented are the mean \pm standard deviation for continuous variables and as the percentage of total patients for categoric variables. The independent sample $t$ test and chi-square or Mann-Whitney test were used for comparison of continuous and categoric variables, as appropriate. All $P$ values were 2 sided. Calculations were performed with the Statistical Package for the Social Sciences version 12.0 (SPSS Inc, Chicago, Ill).

\section{RESULTS}

We enrolled a total of 50 patients ( $56 \%$ were male), with 25 patients in each group. The effective radiation dose was approximated as $12 \pm 5 \mathrm{mSv}$ for the AS group and $10 \pm 3$ $\mathrm{mSv}$ for the control group. There was no significant difference between the AS and control groups in age (79.7 \pm 8.1 years vs $76.0 \pm 6.7$ years, respectively; $P=.07$ ) or baseline left ventricular ejection fraction $(49 \% \pm 15 \%$ vs $48 \%$ $\pm 13 \%$, respectively; $P=.80$ ). Compared with controls, patients with AS had a worse New York Heart Association functional class $(2.8 \pm 0.7$ vs $1.6 \pm 0.7 ; P<.01)$. The logistic euroSCORE was $28 \% \pm 14 \%$ for the AS group. Detailed baseline clinical characteristics for both groups are shown in Table 1.

\section{Aortic Root Longitudinal Dimensions}

Compared with the control group, the AS group showed a reduced distance from the aortic valve annulus to the left coronary artery ostium $(13.4 \pm 3.2 \mathrm{~mm}$ vs $15.6 \pm 2.7$ $\mathrm{mm} ; P=.01)$. There was a similar reduction in the distance from the aortic valve annulus to the right coronary artery ostium in the AS group compared with the control group $(13.6 \pm 2.8$ vs $15.2 \pm 2.5 \mathrm{~mm} ; P=.04)$. The longitudinal distance from the aortic valve annulus to the sinotubular junction was also reduced in the AS group compared with the control group $(16.7 \pm 2.0$ vs $21.0 \pm 2.3 \mathrm{~mm} ; P<.01)$. Similar changes were observed for these variables during both systole and diastole (Table 2). In the subset of 4 patients 

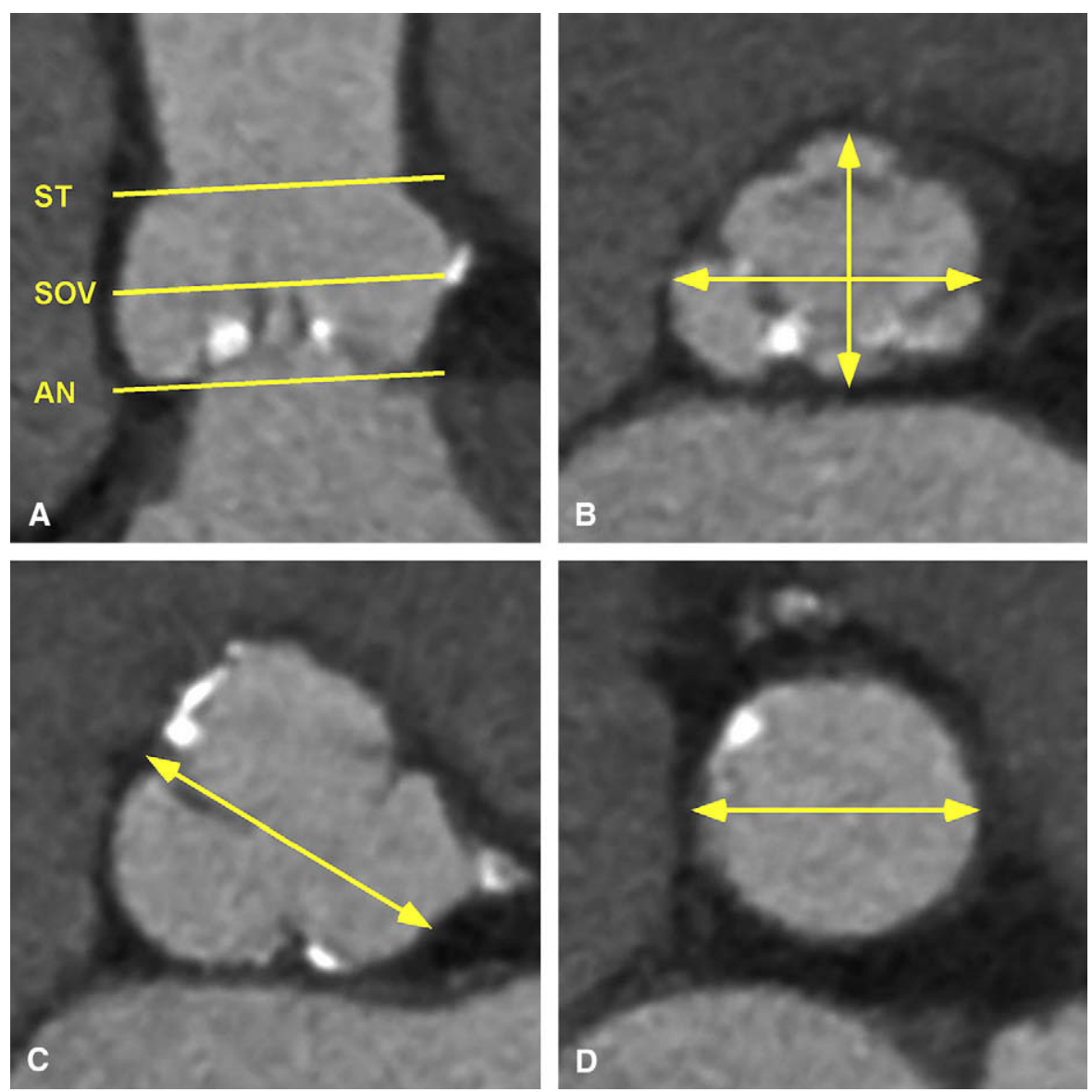

FIGURE 1. Long-axis (A) and corresponding short-axis views of the aortic valve annulus (B), sinuses of Valsalva (C), and sinotubular junction (D). Measurements of the sinuses of Valsalva were made from the commissures between 2 cusps to the middle of the opposite cusp (C). Measurements at the other levels of the aortic root were made using the largest cross-sectional diameter from the short-axis image. ST, Sinotubular; SOV, sinuses of Valsalva; AN, annulus.

who underwent MDCT scanning after PAVR, the distance from the superior aspect of the device to the coronary artery ostia was $2.5 \pm 0.5 \mathrm{~mm}$.

\section{Aortic Root Diameters}

There was no significant difference in the diameters of the left ventricular outflow tract, aortic valve annulus, sinuses of Valsalva, or sinotubular junction between the AS and control groups (Table 3). An oval annulus was present in $36 \%$ of the AS group and $44 \%$ of the control group $(P=$ NS). The aortic annulus was measured to be $27.2 \pm 3.5$ $\mathrm{cm}$ by MDCT and $22.9 \pm 1.3 \mathrm{~cm}$ by transthoracic echocardiography with a correlation coefficient of 0.52 .

\section{Aortic Valve Characteristics}

The mean aortic valve area in the AS group by transthoracic echocardiography was $0.7 \pm 0.1 \mathrm{~cm}^{2}$ (continuity equation) with peak and mean pressure gradients across the aortic valve of $75 \pm 17 \mathrm{~mm} \mathrm{Hg}$ and $43 \pm 11 \mathrm{~mm} \mathrm{Hg}$, respectively. The measured aortic valve area by planimetry on MDCT of
$0.8 \pm 0.2 \mathrm{~cm}^{2}$ was higher than the aortic valve area of $0.7 \pm$ $0.1 \mathrm{~cm}^{2}$ by transthoracic echocardiography $(P<.01)$ with a correlation coefficient of 0.42 . The systolic valve orifice in the AS group was symmetric and star-shaped in $76 \%$, and asymmetric in $24 \%$.

The free margin lengths of the right, left, and noncoronary cusps were all reduced in the AS group versus the control group (Table 4), typically by a distance of 3 to $4 \mathrm{~mm}$ for each cusp. The effective height of the left and noncoronary cusps was greater in the AS group versus the control group, with a trend toward increased effective height of the right coronary cusp in the AS group (Table 4). There was no significant difference in leaflet height between the AS and control groups.

\section{DISCUSSION}

In this study, we compared morphologic characteristics of the aortic root and valve in patients with severe calcific degenerative AS referred for PAVR versus elderly gendermatched controls without AS. Our findings indicate that 


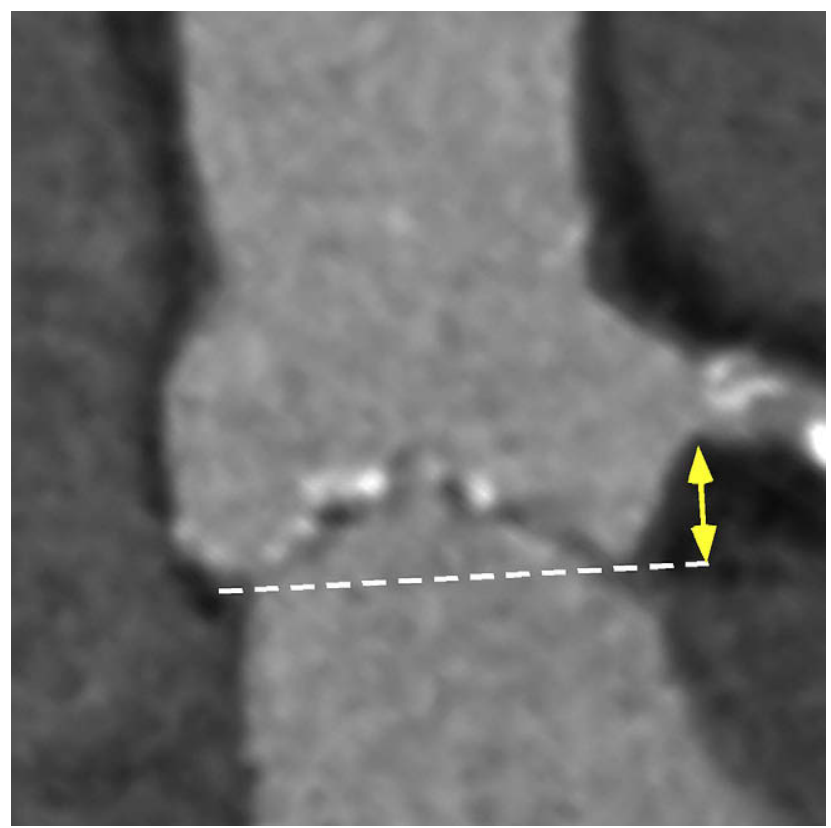

FIGURE 2. Imaging plane used to measure the distance from the aortic valve to the inferior margin of the coronary ostia. Measurements were made from the oblique coronal view during systole. The left coronary artery is shown in this image.

longitudinal remodeling of the aortic root occurs in patients with calcific AS, as manifested by reduced distances from the aortic valve annulus to the coronary artery ostia and sinotubular junction. These differences along the longitudinal axis of the root occurred without any significant change in cross-sectional diameters of the aortic root at the level of the left ventricular outflow tract, annulus, sinuses of Valsalva, or sinotubular junction. Figure 5 illustrates these changes in the AS versus control groups.
These results have important implications for the deployment and design of PAVR devices. Preoperative knowledge of aortic root dimensions, and in particular the relationship of the coronary arteries to the valve annulus and cusps, is critical for optimal positioning of the PAVR device relative to the valve annulus. The absolute difference in distance from the annulus to the coronary artery ostia between the AS and control groups was only 2.6 to $2.8 \mathrm{~mm}$. However, these small distances become clinically relevant when one considers that the average distance between the superior aspect of the prosthesis and the inferior margin of the coronary artery ostia was only $2.5 \pm 0.5 \mathrm{~mm}$ and that the typically calcified leaflet margins are displaced against the stent in the sinus of Valsalva. Placement of the valve too high with respect to the annulus has been associated with coronary complications or severe aortic regurgitation, ${ }^{4}$ whereas an inferior placement of the valve relative to the annulus can lead to transient or permanent complete heart block. Patients in whom the distance from the annulus to the coronary artery ostia is markedly reduced may require placement of an angioplasty guidewire into the affected coronary artery before device deployment to facilitate intervention with a coronary stent in the event of a coronary artery occlusion by the device.

In the context of future PAVR device design, the finding of a reduced distance between the annulus and the coronary artery ostia in patients with calcific degenerative AS suggests that PAVR devices must be designed with either a low profile or an open design near the apex of the device to minimize the risk of coronary complications. There is ongoing research into improvements of future device generations beyond modification of the profile alone. Furthermore, the development of devices that could be repositioned after initial expansion of the device within the
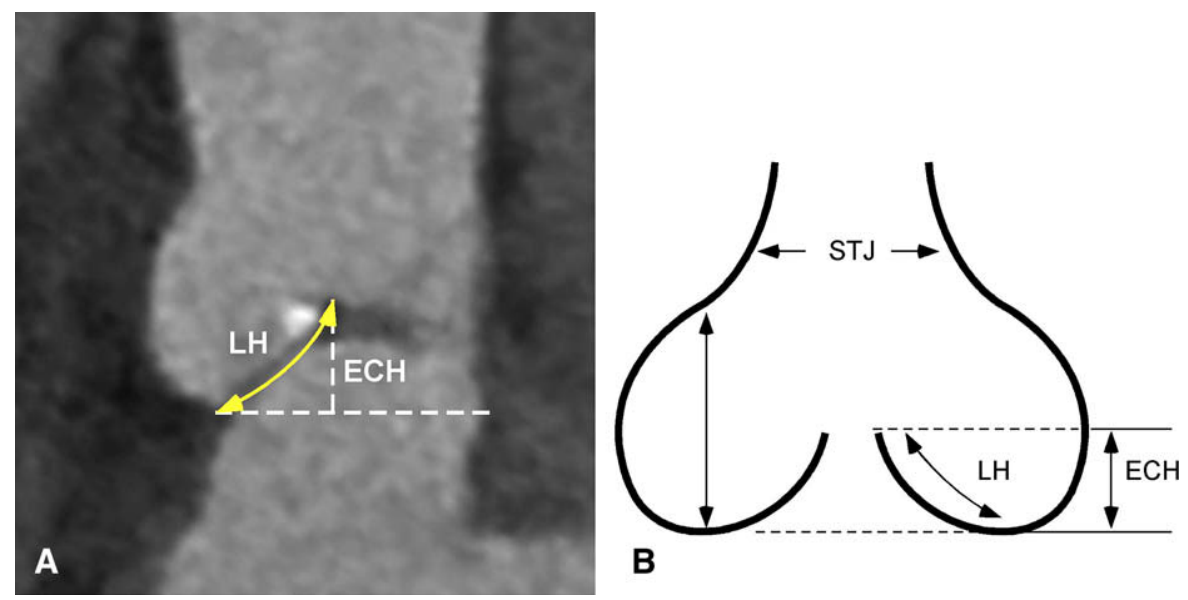

FIGURE 3. Imaging plane used to define the leaflet height and effective cusp height. A, Leaflet height, defined as the longest length of the cusp from the annulus to the cusp tip, was measured in diastole from the long-axis view going through the center of each cusp. Effective cusp height, defined as the vertical distance between the cusp from the annulus to the cusp tip, was measured in diastole from the same plane as the cusp height. B, Schematic diagram illustrating leaflet height and effective cusp height. STJ, Sinotubular junction; $L H$, leaflet height; $E C H$, effective cusp height. 


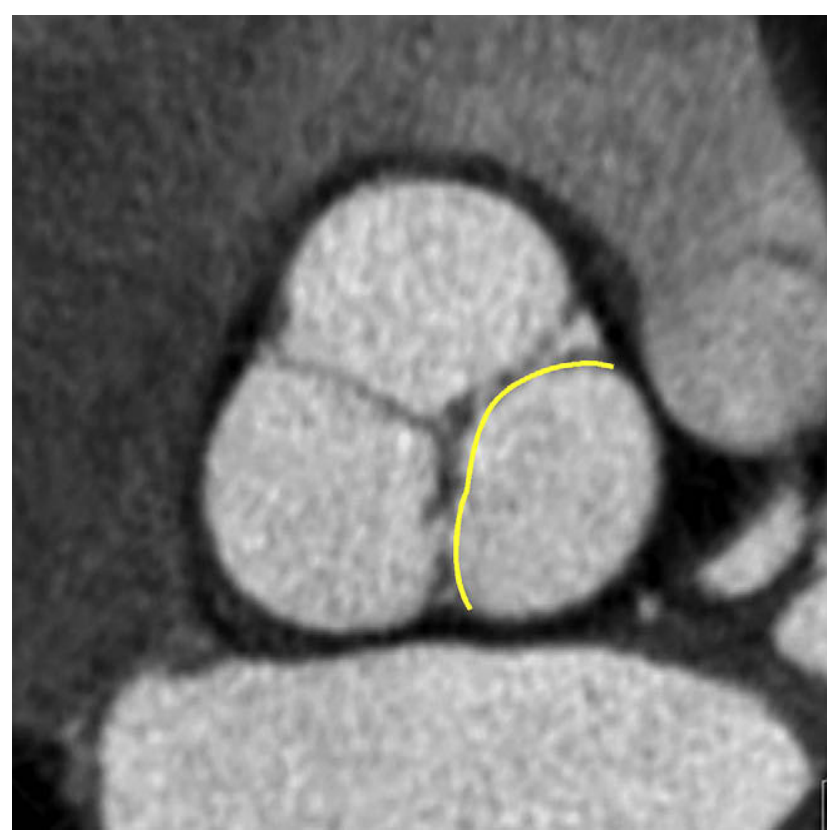

FIGURE 4. The free margin length of each cusp was measured during diastole from the short-axis view.

aortic root would help minimize suboptimal device expansion or placement, especially in patients with small aortic roots in which the margin for error in device deployment is particularly low. Three-dimensional MDCT data are increasingly used in the process of device development.

The emergence of PAVR has focused clinical and imaging interest on the aortic root. However, earlier data regard-

TABLE 1. Baseline clinical characteristics in aortic stenosis group versus controls

\begin{tabular}{|c|c|c|c|}
\hline Variable & $\begin{array}{l}\text { Aortic stenosis } \\
\quad(\mathbf{n}=\mathbf{2 5})\end{array}$ & $\begin{array}{l}\text { Controls } \\
(\mathbf{n}=\mathbf{2 5})\end{array}$ & $\begin{array}{c}P \\
\text { value }\end{array}$ \\
\hline Age (y) & $79.7 \pm 8.1$ & $76.0 \pm 6.7$ & .07 \\
\hline Male gender \% (n) & $56(12)$ & $56(12)$ & \\
\hline Body surface area $\left(\mathrm{m}^{2}\right)$ & $1.8 \pm 0.2$ & $2.0 \pm 0.3$ & .19 \\
\hline Diabetes mellitus \% (n) & $36(9)$ & $28(5)$ & .25 \\
\hline Hypertension \% (n) & $88(22)$ & $94(17)$ & .23 \\
\hline Dyslipidemia \% (n) & $92(23)$ & $72(13)$ & .07 \\
\hline Active smoker $\%$ & 0 & 0 & \\
\hline History of CAD \% (n) & $75(18)$ & $45(10)$ & .13 \\
\hline Prior CABG \% (n) & $33(8)$ & $14(3)$ & .14 \\
\hline Prior PCI \% (n) & $29(7)$ & $21(4)$ & .34 \\
\hline NYHA class $\%(n)$ & & & $<.01$ \\
\hline I & $4(1)$ & $48(12)$ & \\
\hline II & $20(5)$ & $40(10)$ & \\
\hline III & $64(16)$ & $12(3)$ & \\
\hline IV & $12(3)$ & 0 & \\
\hline $\begin{array}{l}\text { Left ventricular ejection } \\
\text { fraction }(\%)\end{array}$ & $49 \pm 15$ & $48 \pm 13$ & .80 \\
\hline
\end{tabular}

TABLE 2. Aortic root longitudinal dimensions in aortic stenosis group versus controls

\begin{tabular}{lccr}
\hline \multicolumn{1}{c}{ Variable } & $\begin{array}{c}\text { Aortic stenosis } \\
(\mathbf{n = 2 5})\end{array}$ & $\begin{array}{c}\text { Controls } \\
(\mathbf{n = 2 5})\end{array}$ & $\begin{array}{c}\boldsymbol{P} \\
\text { value }\end{array}$ \\
\hline $\begin{array}{l}\text { Aortic valve annulus to LCA } \\
\text { in systole (mm) }\end{array}$ & $13.4 \pm 3.2$ & $15.6 \pm 2.7$ & .01 \\
$\begin{array}{l}\text { Aortic valve annulus to LCA } \\
\quad \text { in diastole (mm) }\end{array}$ & $13.3 \pm 2.3$ & $15.7 \pm 2.6$ & $<.01$ \\
$\begin{array}{l}\text { Aortic valve annulus to RCA } \\
\quad \text { in systole (mm) }\end{array}$ & $13.6 \pm 2.8$ & $15.2 \pm 2.5$ & .04 \\
$\begin{array}{l}\text { Aortic valve annulus to RCA } \\
\text { in diastole (mm) }\end{array}$ & $13.4 \pm 2.2$ & $15.6 \pm 2.7$ & $<.01$ \\
$\begin{array}{l}\text { Aortic valve annulus to ST } \\
\text { junction in systole (mm) }\end{array}$ & $16.7 \pm 2.0$ & $21.0 \pm 2.3$ & $<.01$ \\
$\begin{array}{l}\text { Aortic valve annulus to ST } \\
\text { junction in diastole (mm) }\end{array}$ & $17.3 \pm 2.1$ & $21.4 \pm 2.4$ & $<.01$ \\
\hline LCA, Left coronary artery; $R C A$, right coronary artery; $S T$, sinotubular. &
\end{tabular}

ing changes in aortic root morphology in calcific AS are limited. In a study using transesophageal echocardiography, Ben-Dor and colleagues ${ }^{16}$ reported reduced diameters of the aortic sinus and sinotubular junction in 62 patients with degenerative tricuspid AS compared with controls. In comparison, in a retrospective study using both transthoracic and transesophageal echocardiography, Crawford and Roldan ${ }^{17}$ found a reduced aortic annulus size but an increased diameter of the sinotubular junction in 42 patients with AS compared with controls. We found no significant change in the cross-sectional diameters of the aortic root in AS compared with these studies. The differing results between these studies are likely due to enrollment of different patient populations, as well as inherent differences between MDCT and echocardiographic measurements of the aortic root. BenDor and colleagues excluded patients with a bicuspid aortic valve or greater than mild aortic insufficiency, whereas $75 \%$ of the patients in the study by Crawford and Roldan had at least mild aortic insufficiency and $13 \%$ had a bicuspid aortic valve.

Our study demonstrates subtle differences of measurements between MDCT and echocardiography. Although standard 2-dimensional echocardiography remains the clinical standard for the anatomic and functional assessment of

TABLE 3. Aortic root diameters by computed tomography in aortic stenosis group versus controls

\begin{tabular}{lccc}
\hline \multicolumn{1}{c}{ Variable } & $\begin{array}{c}\text { Aortic stenosis } \\
(\mathbf{n = 2 5})\end{array}$ & $\begin{array}{c}\text { Controls } \\
(\mathbf{n = 2 5})\end{array}$ & $\begin{array}{c}\boldsymbol{P} \\
\text { value }\end{array}$ \\
\hline LVOT diameter $(\mathrm{mm})$ & $24.6 \pm 3.6$ & $25.1 \pm 3.0$ & .65 \\
Annulus diameter $(\mathrm{mm})$ & $27.2 \pm 3.5$ & $27.2 \pm 4.0$ & .99 \\
Annulus area $\left(\mathrm{cm}^{2}\right)$ & $6.0 \pm 1.6$ & $6.7 \pm 1.7$ & .18 \\
Aortic sinus diameter $(\mathrm{mm})$ & $34.7 \pm 4.7$ & $36.7 \pm 5.3$ & .17 \\
ST junction diameter $(\mathrm{mm})$ & $27.1 \pm 3.8$ & $28.2 \pm 4.7$ & .40 \\
Ascending aorta diameter $(\mathrm{mm})$ & $32.8 \pm 4.2$ & $32.2 \pm 5.8$ & .72 \\
\hline
\end{tabular}

LVOT, Left ventricular outflow tract; $S T$, sinotubular. 
TABLE 4. Characteristics of the aortic valve in aortic stenosis group versus controls

\begin{tabular}{lccc}
\hline \multicolumn{1}{c}{ Variable } & $\begin{array}{c}\text { Aortic stenosis } \\
(\mathbf{n}=\mathbf{2 5})\end{array}$ & $\begin{array}{c}\text { Controls } \\
(\mathbf{n = 2 5})\end{array}$ & $\begin{array}{c}\boldsymbol{P} \\
\text { value }\end{array}$ \\
\hline Aortic valve area $\left(\mathrm{cm}^{2}\right)$ & $0.8 \pm 0.2$ & $2.7 \pm 0.8$ & $<.001$ \\
RCC free margin length $(\mathrm{mm})$ & $27.2 \pm 5.0$ & $31.4 \pm 4.9$ & $<.01$ \\
LCC free margin length $(\mathrm{mm})$ & $26.5 \pm 4.9$ & $31.0 \pm 4.5$ & $<.01$ \\
NCC free margin length $(\mathrm{mm})$ & $28.1 \pm 5.6$ & $32.3 \pm 4.6$ & $<.01$ \\
RCC height $(\mathrm{mm})$ & $14.5 \pm 2.2$ & $15.5 \pm 1.8$ & .08 \\
LCC height $(\mathrm{mm})$ & $15.7 \pm 2.0$ & $15.5 \pm 2.6$ & .76 \\
NCC height $(\mathrm{mm})$ & $16.2 \pm 3.1$ & $16.3 \pm 2.9$ & .93 \\
RCC effective height $(\mathrm{mm})$ & $9.0 \pm 1.5$ & $8.2 \pm 1.5$ & .06 \\
LCC effective height $(\mathrm{mm})$ & $9.0 \pm 1.3$ & $7.9 \pm 1.6$ & $<.01$ \\
NCC effective height $(\mathrm{mm})$ & $9.7 \pm 2.0$ & $8.3 \pm 1.9$ & .02 \\
\hline
\end{tabular}

$R C C$, Right coronary cusp; $L C C$, left coronary cusp; $N C C$, noncoronary cusp; $R C A$, right coronary artery; $L C A$, left coronary artery.

the aortic valve, 3-dimensional datasets acquired with MDCT or potentially 3-dimensional echocardiography allow manipulation in complex, oblique planes resulting in true cross-sectional measurements. Defining the aortic annulus at the lowest level of the valve cusp insertion, our MDCT data demonstrated an oval annulus in $36 \%$ of patients in the AS group, and the maximum annulus diameter was larger in comparison with echocardiography. The finding of an oval annulus by MDCT has been described, and anatomic studies have demonstrated that the true shape of the annulus is not circular but rather crown shaped. ${ }^{18}$ Additional studies are needed to determine the role of preoperative and intraopera- tive imaging for optimal sizing and positioning of the PAVR device at the annulus. Our study also demonstrated only a modest degree of correlation in planimetered aortic valve area by MDCT versus the calculated aortic valve area using valvular gradients by Doppler echocardiography, with a slight overestimation of aortic valve area by MDCT, similar to other studies evaluating the use of MDCT in measuring aortic valve area. ${ }^{19-22}$ It should be noted, however, that the measurement of aortic valve area by velocity (Doppler imaging) or pressure gradients (cardiac catheterization) across the valve is inherently a measure of functional valve area. $^{23-25}$ This functional valve area reflects the average of measurements throughout the duration of aortic valve opening during systole, as well as the physiologic effects of multiple variables, such as coexisting aortic or mitral regurgitation. Planimetry of the aortic valve using MDCT, on the other hand, is a simple anatomic measurement of maximal valve area in systole. However, 4-dimensional MDCT does provide detailed information on the shape and symmetry of valve opening and its relationship to leaflet calcification, which could be important for symmetric device deployment. Although comparative data evaluating the respective merits of different imaging modalities in patients undergoing PAVR are limited, it is likely that these modalities provide complementary information.

Our findings of reduced distances between the annulus to coronary ostia and sinotubular junction provide evidence for remodeling along the longitudinal axis of the aortic root. The lack of significant differences in cross-sectional dimensions
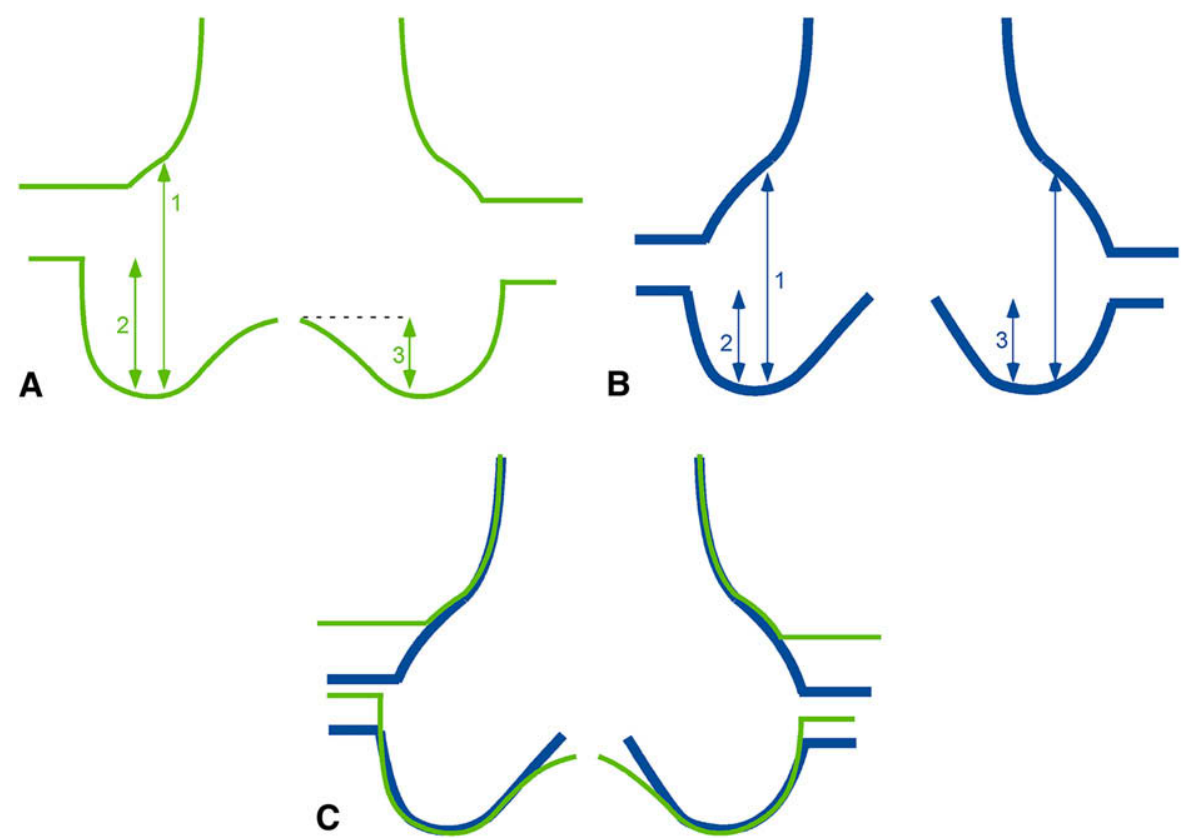

FIGURE 5. Changes in aortic root morphology in AS. A, Normal aortic root (green). B, Aortic root in AS (blue). Compared with controls, distances from aortic valve annulus to sinotubular junction (1) and aortic valve annulus to left or right coronary artery ostia (2) are reduced. The effective cusp height (3) is increased in AS group compared with controls. C, Overlapping aortic root for AS and control groups. 
of the left ventricular outflow tract, annulus, sinuses of Valsalva, or sinotubular junction between the 2 groups suggests that remodeling of the aortic root along the horizontal dimension does not occur in AS. Our findings of reduced cusp-free margin length and alterations in effective cusp height (the vertical distance from the annulus to each cusp tip) in the AS group are consistent with the dystrophic changes that occur in patients with this disease. ${ }^{26}$

The current study was not designed to assess procedural outcome and does not provide insight into potential pathophysiologic mechanisms of aortic root remodeling in these patients with calcific AS. Previous studies have described root remodeling mainly in the context of aortic dilatation, hypertension, and aortic valve regurgitation. ${ }^{27}$ Underlying pathophysiologic processes, including cystic medial necrosis and fibrosis, have been described. ${ }^{28,29}$ Recent insights into degenerative aortic valve stenosis emphasize a complex interaction between inflammatory response and calcification. ${ }^{26}$ However, better understanding of these complex and dynamic processes will require ex vivo models, modeling of hemodynamic effects, and serial imaging. ${ }^{30}$

\section{CONCLUSIONS}

The results of our study suggest that longitudinal remodeling of the aortic root occurs in calcific AS, as manifested by reduced distances from the aortic valve annulus to the coronary artery ostia and sinotubular junction. These findings have important implications for the design and deployment of PAVR devices.

\section{References}

1. Webb JG, Pasupati S, Humphries K, Thompson C, Altwegg L, Moss R, et al. Percutaneous transarterial aortic valve replacement in selected high-risk patients with aortic stenosis. Circulation. 2007;116:755-63.

2. Cribier A, Eltchaninoff H, Tron C, Bauer F, Agatiello C, Sebagh L, et al. Early experience with percutaneous transcatheter implantation of heart valve prosthesis for the treatment of end stage inoperable patients with calcific aortic stenosis. $J \mathrm{Am}$ Coll Cardiol. 2004;43:698-703.

3. Lichtenstein SV, Cheung A, Ye J, Thompson CR, Carere RG, Pasupati S, et al. Transapical transcatheter aortic valve implantation in man. Circulation. 2006; 114:591-6.

4. Webb JG, Chandavimol M, Thompson CR, Ricci DR, Carere RG, Munt BI, et al. Percutaneous aortic valve implantation retrograde from the femoral artery. $\mathrm{Circu}$ lation. 2006;113:842-50.

5. Schoenhagen P, Greenberg RK. 3-dimensional planning of endovascular procedures with multi-detector computed tomography: impact on procedural results and clinical outcome? Int J Cardiovasc Imaging. 2008;24:211-3. Epub 2007 Aug 17.

6. Otsuka M, Sugahara S, Nakamura M, Umeda K, Bonkohara Y, Van Pelt N, et al. Optimal fluoroscopic view selection for percutaneous coronary intervention by multislice computed tomography. Int J Cardiol. 2007;118:94-6.

7. Hayabuchi Y, Mori K, Kagami S. Virtual endoscopy using multi-detector row CT for coil occlusion of patent ductus arteriosus. Catheter Cardiovasc Interv. 2007; 70:434-9.
8. Graham LN, Melton IC, MacDonald S, Crozier IG. Value of CT localization of the fossa ovalis prior to transseptal left heart catheterization for left atrial ablation. Europace. 2007;9:417-23.

9. Chen MY, Jehle AJ, Quaife RA, Carroll JD. Cardiac computed tomographic angiography pre-procedural planning for percutaneous atrial septal defect closure. J Cardiovasc Computed Tomography. 2007;1:S4.

10. Cademartiri F, Nieman K, van der Lugt A, Raaijmakers RH, Mollet N, Pattynama PM, et al. Intravenous contrast material administration at 16-detector row helical CT coronary angiography: test bolus versus bolus-tracking technique. Radiology. 2004;233:817-23.

11. Morin RL, Gerber TC, McCollough CH. Radiation dose in computed tomography of the heart. Circulation. 2003;107:917-22.

12. Anderson RH. Clinical anatomy of the aortic root. Heart. 2000;84:670-3.

13. Schafers HJ, Bierbach B, Aicher D. A new approach to the assessment of aortic cusp geometry. $J$ Thorac Cardiovasc Surg. 2006;132:247-9.

14. Dumesnil JG, Honos GN, Lemieux A, Beauchemin J. Validation and application of indexed aortic prosthetic valve areas calculated by Doppler echocardiography. J Am Coll Cardiol. 1990;16:637-43.

15. Schiller NB, Shah PM, Crawford M, DeMaria A, Devereux R, Feigenbaum H, et al. Recommendations for quantitation of the left ventricle by two-dimensional echocardiography. American Society of Echocardiography Committee on Standards, Subcommittee on Quantitation of Two-Dimensional Echocardiograms. J Am Assoc Echocardiogr. 1989;2:358-67.

16. Ben-Dor I, Sagie A, Weisenberg D, Zekry SB, Fraser A, Sahar G, et al. Comparison of diameter of ascending aorta in patients with severe aortic stenosis secondary to congenital versus degenerative versus rheumatic etiologies. Am J Cardiol. 2005;96:1549-52.

17. Crawford MH, Roldan CA. Prevalence of aortic root dilatation and small aortic roots in valvular aortic stenosis. Am J Cardiol. 2001;87:1311-3.

18. Tops LF, Wood DA, Delgado V, Schuijf JD, Mayo JR, Pasupati S, et al. Noninvasive evaluation of the aortic root by multislice computed tomography. J Am Coll Cardiol Imaging. 2008;1:321-30.

19. Alkadhi H, Wildermuth S, Plass A, Bettex D, Baumert B, Leschka S, et al. Aortic stenosis: comparative evaluation of 16-detector row $\mathrm{CT}$ and echocardiography. Radiology. 2006;240:47-55.

20. Pouleur AC, le Polain de Waroux JB, Pasquet A, Vanoverschelde JL, Gerber BL. Aortic valve area assessment: multidetector CT compared with cine MR imaging and transthoracic and transesophageal echocardiography. Radiology. 2007;244: 745-54.

21. Laissy JP, Messika-Zeitoun D, Serfaty JM, Sebban V, Schouman-Claeys E, Iung $\mathrm{B}$, et al. Comprehensive evaluation of preoperative patients with aortic valve stenosis: usefulness of cardiac multidetector computed tomography. Heart. 2007; 93:1121-5.

22. Feuchtner GM, Muller S, Bonatti J, Schachner T, Velik-Salchner C, Pachinger O, et al. Sixty-four slice CT evaluation of aortic stenosis using planimetry of the aortic valve area. Am J Roentgenol. 2007;189:197-203.

23. Naqvi TZ, Siegel RJ. Aortic stenosis: the role of transesophageal echocardiography. Echocardiography. 1999;16(7 Pt 1):677-88.

24. Maslow AD, Mashikian J, Haering JM, Heindel S, Douglas P, Levine R. Transesophageal echocardiographic evaluation of native aortic valve area: utility of the double-envelope technique. J Cardiothorac Vasc Anesth. 2001;15:293-9.

25. Mochizuki Y, Pandian NG. Role of echocardiography in the diagnosis and treatment of patients with aortic stenosis. Curr Opin Cardiol. 2003;18:327-33.

26. Goldberg SH, Elmariah S, Miller MA, Fuster V. Insights into degenerative aortic valve disease. J Am Coll Cardiol. 2007;50:1205-13.

27. Palmieri V, Bella JN, Arnett DK, Roman MJ, Oberman A, Kitzman DW, et al. Aortic root dilatation at sinuses of Valsalva and aortic regurgitation in hypertensive and normotensive subjects: The Hypertension Genetic Epidemiology Network Study. Hypertension. 2001;37:1229-35.

28. Schlatmann TJ, Becker AE. Histologic changes in the normal aging aorta: implications for dissecting aortic aneurysm. Am J Cardiol. 1977;39:21-6.

29. Carlson RG, Lillehei CW, Edwards JE. Cystic medial necrosis of the ascending aorta in relation to age and hypertension. Am J Cardiol. 1970;25:411-5.

30. Beller CJ, Labrosse MR, Thubrikar MJ, Szabo G, Robicsek F, Hagl S. Increased aortic wall stress in aortic insufficiency: clinical data and computer model. Eur J Cardiothorac Surg. 2005;27:270-5. 